\title{
CAMBIO POLÍTICO EN FRANCIA: ¿HACIA LA VI REPÚBLICA?
}

\author{
POR \\ JAVIER TAJADURA TEJADA \\ Profesor Titular de Derecho Constitucional \\ en la Universidad del País Vasco
}

\section{PARADOJAS FRANCESAS}

Francia es un país de paradojas. Quizás la mayor de ellas sea el hecho de que la quinta economía mundial y un país en el que gustosamente viviría el noventa por ciento de la población mundial si pudiera hacerlo, se perciba a sí mismo como un país en declive, en profunda crisis, política, económica y social. Ha sido "La France qui tombe", tal y como la describe Nicolas Baverez en un libro con el mismo título, la que ha elegido a Sarkozy para que ponga fin a esa supuesta decadencia. Es cierto que en Francia viven dos millones de pobres y cinco millones de desempleados, pero la brecha entre pobres y ricos es mucho menor que la existente en Estados Unidos o en el Reino Unido. Los recién nacidos tienen más posibilidades de sobrevivir en Francia que en Estados Unidos. De la misma forma la esperanza de vida de los franceses es mayor que la de los norteamericanos. Aun con sus defectos, la calidad de su sistema educativo, sanitario y de transportes no puede ser despreciado. Es verdad que el nivel de desempleo juvenil es elevado, pero disminuiría notablemente si los jóvenes franceses de color de 18 a 30 1996).

1 Javier Tajadura Tejada es autor de "La V República francesa» (Pamplona, 
años fueran trasladados de las filas del paro a la cárcel como sucede en los Estados Unidos.

Sea de ello lo que fuere, ha sido esta percepción ampliamente compartida de crisis nacional la que ha conferido un carácter hasta cierto punto dramático a las últimas elecciones presidenciales. Elecciones en las que se han batido todos los récords de participación de la historia de la V República.

Probablemente la palabra que mejor defina la situación psicológica de los franceses sea el miedo. Los franceses perciben una gran sensación de inseguridad y tienen miedo, miedo sobre todo al futuro. En ese contexto, y en coherencia con la relevante posición que la Constitución gaullista atribuye al Jefe del Estado, los franceses buscaban un líder fuerte, alguien que les reportara seguridad.

La Jefatura del Estado reviste en Francia todos los caracteres de lo que el historiador norteamericano Arthur Schlesinger calificó como "Presidencia Imperial». El Presidente de la República dirige la política exterior y defensa, controla el arsenal nuclear, nombra y cesa al primer ministro, puede convocar referendos y disolver el Parlamento. Sus facultades (al margen de la cláusula de plenos poderes del artículo 16) son tan amplias que no resulta exagerada la afirmación de que, en cierta medida, la democracia en Francia depende de la Presidencia de la República.

Los franceses anhelaban a un hombre fuerte $y$, al mismo tiempo, a alguien que les garantizase un cambio, que les ofreciese la posibilidad de superar la crisis y los miedos. En este sentido, el director de "Le Monde" advirtió que el nuevo Presidente o Presidenta sería aquel que supiera llegar desde la emoción, al corazón de los franceses.

Ello explica que la campaña electoral girase sobre temas tales como el orgullo nacional, el restablecimiento de la autoridad, los riesgos de la inmigración incontrolada, la inseguridad pública, etc. Sarkozy ha sido elegido Presidente con un programa basado en la necesidad de rehabilitar el orden, el trabajo, y la patria. Nunca como hasta ahora se había constatado con tanta claridad lo que el gran jurista Robert Badinter, antiguo Ministro de Justicia y Presidente del Consejo Constitucional, denominó ya en los inicios de los años noventa, la lepenización de los espíritus. La lepenización de Francia. Le Pen, aunque resultó perdedor en las elecciones, consiguió que el debate político se centrara en los temas que le son propios: la inmigración y la inseguridad. Ahora bien, planteado el debate en estos términos, la candidata socialista, Ségolène Royal partía en clara desventaja. Si de lo que se trataba era únicamente de 
determinar quién era el campeón de la ley y del orden, quién podría garantizar mejor el restablecimiento de la autoridad en todos los ámbitos, parecía bastante claro que Sarkozy sería el elegido del pueblo francés. La candidata socialista no se esforzó por modificar la agenda del debate político, sino que contribuyó a reforzarlo haciendo importantes y polémicas propuestas en la misma dirección de fortalecimiento de la autoridad y del sentimiento nacional. De esta manera, durante toda la campaña jugó en terreno contrario y, lógicamente, resultó derrotada.

Nicolas Sarkozy, es un buen tribuno y gran orador, autor de frases brillantes; es un político tenaz, dotado de una ambición ilimitada. Cuando fue elegido alcalde de Neuilli, con 28 años proclamó ya que su objetivo era la Presidencia de la República. Presentándose como el adalid del cambio ante una Francia hastiada de su presente y temerosa de su futuro ha logrado hacer realidad su sueño.

La victoria de Sarkozy pone de manifiesto otra gran paradoja. Consiste en subrayar que el electorado francés ha optado por el cambio y en presentar, por tanto, a Nicolas Sarkozy como la encarnación de ese cambio. Ahora bien, interpretar el resultado electoral en clave de cambio exige, inexcusablemente, precisar cuál es el significado y alcance de ese cambio, esto es, en qué consiste el cambio que Sarkozy representa. $Y$ es aquí donde las paradojas se multiplican. El nuevo Presidente ha pretendido sintetizar su voluntad de renovación en todos los órdenes, político, económico, social, cultural e ideológico, en el entierro del espíritu de Mayo del 68 al que atribuye la mayor parte de los problemas de Francia. Como estrategia electoral la idea ha resultado exitosa. Sarkozy ha atribuido la responsabilidad de la situación actual de Francia a unos hechos que tuvieron lugar hace cuatro décadas, y de esa forma, ha conseguido exonerarse él mismo. Porque lo que no se puede ni se debe olvidar es que el nuevo Presidente francés ha sido durante los últimos cinco años el número dos del Gobierno francés por lo que resulta evidente que alguna responsabilidad tendrá en la situación que él denuncia. La candidata socialista tampoco fue capaz de desmontar ese discurso falaz. $Y$ lo cierto es que los franceses que querían un cambio eligieron a Sarkozy. Por el contrario, el discurso defensivo de Royal se identificaba más con la continuidad. Con la continuidad de un modelo que hacía crisis.

No es este el lugar para desmontar el discurso maniqueo y simplista sobre mayo del 68 que sostiene el nuevo Presidente. Como todo fenómeno histórico, los acontecimientos de mayo del 68 tuvieron sus luces y sus sombras, produjeron efectos claramente beneficiosos, e, indudablemente otros secundarios, o "colaterales" que diríamos hoy, que no 
lo eran tanto. En todo caso, el balance global fue indudablemente positivo. El resultado inmediato y plausible de aquellos acontecimientos fue un avance de la libertad y por ello, en términos históricos, debe considerarse un progreso. Por lo que a Sarkozy directamente se refiere, habría que recordarle que antes de mayo del 68 hubiera resultado absolutamente impensable que un hombre divorciado, hijo de inmigrantes, y casado con otra divorciada accediera a la Jefatura del Estado. De la misma forma que hubiera resultado política-ficción imaginar que hubiera disputado el cargo a una mujer soltera con cuatro hijos. Si ello es posible hoy, es gracias a mayo del 68.

En todo caso y al margen de esa estrategia electoral consistente en atribuir la culpa de los males de Francia no a su ineficiente gestión gubernamental sino a hechos acaecidos hace cuarenta años, lo cierto es que el nuevo Presidente ha conseguido presentarse ante los franceses no como el continuador de la obra de Chirac sino como su enterrador. Ello ha sido posible gracias a que Sarkozy ha protagonizado durante los últimos años los episodios más notables de insolidaridad gubernamental que la $V$ República haya conocido. Y que, inexplicablemente, su adversaria no ha sabido explotar. Sarkozy tuvo la osadía de viajar a Washington para disculparse ante el Presidente norteamericano por la negativa de Francia a apoyar la guerra de Irak. Y es que, si Sarkozy hubiera sido Presidente en vez de Chirac, hoy en día la crisis de Francia sería de mucha mayor gravedad en la medida en que las tropas francesas se habrían visto implicadas en la agresión a Irak y serían víctimas del caos actual. Frente al carácter claramente proamericano del nuevo inquilino del Eliseo, Chirac pasará a la historia no tanto por los muchos escándalos de corrupción en que se ha visto implicado, sino por haber sabido decir no a Washington, y de esa forma haber salvaguardado los valores de la razón y del derecho. No es un legado que deba despreciarse.

Por ello, y por las razones que voy a exponer, la contradicción que implica presentar a Sarkozy como una ruptura y no como una continuidad del chiracquismo, es una contradicción aparente. Sarkozy supone en verdad un cambio en la política francesa, y un cambio que por su envergadura puede ser calificado de revolucionario. Su objetivo político no es únicamente enterrar el chiracquismo, del que, paradójcamente, estuvo materialmente desvinculado. Sus propósitos son mucho más ambiciosos y de mayor alcance. En última instancia, la misión política que se ha atribuido es liquidar definitivamente el gaullismo. En este contexto, me propongo en estas páginas responder a los siguientes interrogantes: ¿Cuál es el significado y alcance de la revolución política que Sarkozy representa? (2); En el marco de esta revolución po- 
lítica, ¿cuál es el futuro de la V República?. ¿La Constitución de 1958 puede sobrevivir a la revolución sarkozyana? (3).

\section{LA REVOLUCIÓN POLÍTICA: LA LIQUIDACIÓN DE LOS VALORES Y PRINCIPIOS DEL GAULLISMO}

La victoria de Sarkozy es una victoria histórica porque pone fín a una etapa de la política francesa que ha durado cincuenta años y supone el inicio de una nueva era. Vidal-Beneyto ha puesto de manifiesto cómo la ambición última de Sarkozy es uponer fin, más allá de la secuencia de regímenes y Gobiernos, a la dominación política y sobre todo emblemática del gaullismo, de sus valores, de sus modos y de sus prácticas". Aunque de los cinco Presidentes que ha conocido la V República sólo uno, Mitterrand, perteneciera a la izquierda socialista, todos ellos apostaron por un país abierto a la emigración de cualquier coIor, por uno de los Estados Sociales más completos de Europa, por la independencia frente a los Estados Unidos. Sarkozy es el primer Presidente que ha introducido en su programa el refuerzo de la identidad nacional y medidas restrictivas frente a la inmigración, desgravación de las horas extraordinarias, reducción del número de funcionarios y de los impuestos, atlantismo y relación especial con los Estados Unidos. La gran novedad de la Presidencia Sarkozy es que puede ser el primer Presidente auténticamente de derechas que haya conocido Francia en los últimos 50 años.

Desde una perspectiva puramente formal o de mera imagen, Sarkozy supone una renovación respecto a sus antecesores en el cargo. Resulta difícil recordar alguna imagen de Chirac sin corbata ni traje oscuro. Por el contrario, en la primera foto tras su elección el lunes 7 de mayo, el nuevo presidente no llevaba corbata y vestía pantalones vaqueros. Esto es algo que políticamente puede resultar irrelevante. Ahora bien, en sus primeros días como Presidente se produjeron dos acontecimientos que son sintomáticos de una concepción del Estado completamente diferente de la de sus antecesores. Dichos acontecimientos se reflejaron también en dos fotografías, pero estas trascienden el ámbito de la imagen y anuncian cambios sustanciales. Me refiero a la foto de sus vacaciones en el yate de un importante empresario francés en Malta y a la foto oficial de su primer Gobierno y del primer Consejo de Ministros por él presidido.

La aceptación de la invitación de un importante empresario para disfrutar de unos días de descanso en su yate particular produjo tal conmoción en la sociedad francesa que el nuevo Presidente tuvo que anti- 
cipar su regreso. Sarkozy respondió a sus críticos que sus vacaciones no habían costado ni un euro al Estado francés. Pero con ello en nada tranquilizaba a una opinión pública que, a diferencia de lo que ocurría en la España de Aznar o en la Italia de Berlusconi, no estaba ni está preparada para aceptar la intimidad entre el poder político y el poder económico. Ningún Presidente de la $\mathrm{V}$ República había hecho nunca ostentación de sus relaciones con los titulares del poder económico, ni habían aceptado públicamente regalos de aquellos. Con sus vacaciones en Malta, Sarkozy ha roto un importante tabú: la separación entre el poder político y el poder económico. Ha introducido en Francia el modelo Berlusconi de una forma más sutil y efizaz. Así lo ha denunciado José Vidal Beneyto: "En vez de crear una financiera y desde ella aglutinar los principales poderes económicos del país y sus decisivas prolongaciones mediáticas, se sirve de su despacho de abogados de negocios para constituirse en el soporte jurídico (gubernativo) imprescindible de las grandes empresas francesas y de los principales medios de comunicación, a la par que en el amigo íntimo e imprescindible de sus presidentes". Vidal-Beneyto añade una sucinta relación que corrobora su tesis: Marcel Dassault (armas, Le Figaro, Valeurs Actuelles, etc.); Martín Bouygues (construcción, telefonía, TF1); Arnaud Lagardère (armas, operaciones inmobiliarias, Paris Match, Elle, Journal du Dimanche e importante presencia en Le Monde); Edouard de Rothschild (finanzas, Libération); Vincent Bolloré (transportes marítimos, instalaciones portuarias, publicidad, finanzas, prensa gratuita, producción televisiva, etc.).

Las amistades millonarias de Sarkozy explican igualmente su sorprendente decisión de pasar los quince días de vacaciones de verano en los Estados Unidos, renunciando así a la utilización de las residencias oficiales del Jefe del Estado mantenidas y protegidas durante todo el año. Agnès Crombacck, presidenta de la joyería Tiffany en Francia, y el matrimonio Agostinelli, banquero él y responsable de comunicación de Prada ella, alquilaron en Wolforo junto a un hermoso lago la mansión en la que el nuevo Presidente francés disfrutó de sus vacaciones.

En el esquema ideológico del General de Gaulle, la riqueza y el éxito ocupaban un lugar muy secundario. En el sistema de valores de Sarkozy, por el contrario, la riqueza y el éxito constituyen la columna vertebral.

Por otro lado, la constitución de su primer gobierno también ha supuesto importantes novedades en el panorama político francés. En este sentido se ha subrayado la relevancia simbólica de la paridad entre 
hombres y mujeres, y de la inclusión en el gobierno de ministros como B. Kouchner (Exteriores) o R. Dati (Justicia). Pero estos nombres no desmienten el carácter fuertemente conservador del nuevo Gobierno. El hecho de que Kouccner hubiese formado parte en el pasado de ejecutivos socialistas no puede hacernos olvidar que fue un defensor incondicional de la agresión a Irak, y la brillante magistrada que ha accedido al Ministerio de Justicia no por ser hija de inmigrantes mantiene un discurso más integrador. En todo caso, en mi opinión, lo más significativo del primer Gobierno Sarkozy es el muy reducido número de miembros que lo integran. La espectacular burocracia ministerial de Chirac: treinta ministerios y otras tantas secretarías de Estado rodeadas de innumerables vehículos oficiales y motoristas fue inmediatamente reemplazada por un reducidísimo equipo de gobierno integrado por quince ministros y formado a partes iguales por hombres y mujeres. Pero Chirac no fue el creador de esa estructura. Cierto es que pudo haberla incrementado, pero el fuerte aparato de gobierno y la visible burocracia a su servicio era inherente a la $\mathrm{V}$ República tal y como fue configurada por De Gaulle. El reducido tamaño del Gobierno es un claro presagio de la reducción del tamaño del Estado a la que Sarkozy aspira.

Desde De Gaulle hasta Chirac, todos los Presidentes de la V República confiaron en el Estado como la solución de los problemas: un Estado fuerte. Cuando Sarkozy promete en otra de las múltiples paradojas de su discurso un Estado fuerte está hablando de otra cosa. Sarkozy promete rebajar los impuestos e ir amortizando una de cada dos plazas de funcionario público según se vayan produciendo las jubilaciones. El Estado fuerte de Sarkozy no es el Estado gaullista. Y por ello el conservador Sarkozy puede y debe, ser calificado como un "revolucionario". En relación al número de funcionarios, el programa presidencial propone cubrir sólo una de cada dos vacantes en la función pública, lo que a medio plazo supondría reducir esta en un cincuenta por ciento. Dicha reducción del número de los empleados públicos vendrá acompañada de una importante rebaja fiscal: las reducciones previstas se estima que representarán más de 15.000 millones de euros, a los que hay que añadir la exoneración de los derechos de sucesión que beneficiarán, especialmente, a los franceses de patrimonio más elevado. Cabe temer que los efectos de estas reducciones sobre la calidad de los servicios públicos sean negativos. En última instancia sobre los servicios públicos podía y debía haberse centrado el debate político entre los candidatos a la presidencia. La propuesta de Sarkozy resultó clara e inteligible para la mayoría de los franceses. La de su adversaria socialista, lamentablemente, resultó ambigua, imprecisa, meramente defensiva, partidaria del mero mantenimiento del status quo, carente de una 
reflexión crítica sobre el funcionamiento de los servicios públicos. $Y$ esto es algo que hay que subrayar, porque una cosa es advertir que la reducción del tamaño del Estado proyectada por el nuevo gobierno puede producir efectos traumáticos sobre la cohesión de la sociedad francesa, y otra proclamar que cualquier reforma es innecesaria. El Estado francés está excesivamente burocratizado y requiere reformas en profundidad. Ahora bien, esas reformas pueden y deben ser compatibles con su dimensión social. Durante la campaña electoral Sarkozy ofreció propuestas concretas acompañadas de plazos de ejecución y fórmulas de financiación. Frente a él, la candidata socialista, al no estar preparada por la dirección del partido, jugaba, una vez más, en desventaja. Así, Royal no fue capaz de articular un proyecto reformista convincente. Esa carencia determinó en buena medida su derrota. Así lo ha reconocido el profesor Sami Naïr, miembro del comité de campaña de la candidata socialista: "Ségolène basó su discurso en los valores de transformación de la sociedad, en las costumbres, en la crítica de las relaciones verticales entre los grupos sociales, en la no ocultación de la miseria cotidiana, etcera. Pero una campaña basada en valores no basta; la gente quiere saber en qué se embarca políticamente: qué programa político, qué plazos, cuánto cuesta, quién va a pagar... Y, de hecho, hemos sido poco precisos en esos puntos». Por el contrario, Sarkozy proporcionó a los franceses respuestas precisas a los mencionados interrogantes.

Si lo anterior tiene algún fundamento, creo que resulta bastante claro que Sarkozy pretende hacer frente a la crisis del Estado francés a través de una terapia de choque. Terapia basada en una visión maniquea de la sociedad, en virtud de la cual habría que apostar por la "Francia que se levanta temprano" frente a la Francia "subvencionada». La reducción del Estado que propone es de matriz tatcherista. La revolución de Sarkozy bebe en las fuentes de la revolución conservadora de la Dama de Hierro y de Ronald Reagan. Es ahí donde se encuentran los fundamentos ideológicos del proyecto político de Sarkozy. Ello quiere decir que el viejo gaullismo de tintes sociales será reemplazado por una economía de mercado sin adjetivos. Como ha advertido Carlos Fuentes, Sarkozy representa un «movimiento sin memoria» basado en la "preeminencia del dinero y la sacralización de la competencia por encima de la solidaridad».

Por otro lado, la formación del Gobierno y el establecimiento de numerosos grupos y comisiones de trabajo y estudio sobre diversas reformas ha servido a Sarkozy para plantear una auténtica OPA al Partido Socialista francés, cuyos principales referentes han pasado a trabajar para aquél. Con Kouchner han entrado en el Gobierno Eric Besson, 
Jean-Marie Bockel o Jean-Pierre Jouyet, mientras tres políticos claves de la era Mitterrand, Jacques Attali, Hubert Védrine o Jack Lang, han recibido encargos de preparar informes sobre, respectivamente, los frenos al crecimiento, los problemas de la globalización y la reforma de las instituciones de la $\mathrm{V}$ República. El último en ponerse al servicio del Presidente - hasta ahora - ha sido el antiguo Primer Ministro Michael Rocard, integrándose en un Comité para la revalorización de la profesión docente. Por otro lado, Domenique Strauss-Kahn es postulado por el Gobierno como futuro director del Fondo Monetario Internacional. En este caso hay que subrayar que, Strauss-Kahn, aunque fue derrotado por Royal en las primarias socialistas es percibido hoy por la mayoría del partido y de la opinión pública en general, como uno de los dirigentes más solventes y capaces para superar la crisis del socialismo francés. Con esta astuta y hábil maniobra, Sarkozy elimina a un poderoso rival.

Finalmente, si el proyecto político del nuevo Presidente es socialmente conservador y económicamente desregulador, desde la perspectiva internacional, es manifiestamente atlantista y proamericano. $Y$ de esta forma supone también un rechazo a la última seña de identidad del gaullismo: la independencia frente a Estados Unidos. Ese atlantismo, compatible no obstante, con una profesión de fe europeísta, obedece no tanto a una determinada concepción geoestratégica sobre el lugar de Francia en el mundo como a razones de afinidad ideológica. Ya he dicho cómo, con independencia de que lo reconozca o no expresamente, los referentes políticos de Sarkozy son Tatcher y Reagan. Y ello porque defiende un modelo de sociedad en el que el éxito y la riqueza son los valores supremos. Sarkozy es consciente de que en la medida en que ese modelo es el vigente en Estados Unidos, la alianza con ese país resulta vital para el éxito de su propio proyecto.

En definitiva, si el sistema de valores sobre los que se construyó el gaullismo se caracterizó por la defensa de un Estado fuerte, protector de los débiles, e independiente tanto de los poderes económicos, como de la superpotencia norteamericana, podemos decir que Sarkozy ha expedido ya el certificado de defunción de dicho modelo. Sarkozy ha apostado decididamente por la reducción del Estado, por la fusión más o menos encubierta del poder político y el poder económico, y por un atlantismo incondicional. De Gaulle defendió un Estado fuerte frente a los poderosos, mientras que Sarkozy sólo concibe la fortaleza del Estado para hacer frente a los excluidos del sistema. En este contexto y con estas premisas, no creo que sea exagerado emplear el término revolución. Si Sarkozy tiene éxito y consigue cumplir sus propósitos habrá protagonizado una autentica revolución política. Una revolución 
que más que enterrar al espíritu de mayo del 68, paradójicamente, pondrá fin al modelo ideológico que, en teoría, debería haber defendido. Estas son las razones profundas por las que Sarkozy nunca tuvo el apoyo de Chirac ni de De Villepin. No se trataba sólo de rivalidades personales. Los viejos gaullistas eran plenamente conscientes de las intenciones de Sarkozy. Pero Sarkozy salió vencedor de una guerra abierta por la sucesión de Chirac en la que la debilidad de éste le impidió designar a su favorito, De Villepin. Las consecuencias de aquellas intrigas han llevado al antiguo Primer Ministro a los tribunales. El 27 de julio, los jueces instructores Jean-Marie d'Huy y Henri Pons comunicaron a De Villepin que figura como inculpado en el sumario Clearstream. Se le considera sospechoso de "complicidad en una denuncia calumniosa». Y no sólo de eso, sino también de haber ocultado "un robo, abuso de confianza y complicidad en la utilización de documentos falsos». El ex Primer Ministro declinó responder a los jueces hasta haber estudiado el sumario, y saber si tiene derecho, o no, a ser juzgado por una jurisdicción especial en la medida en que todos los actos que se le reprochan fueron realizados en el marco de sus funciones ministeriales.

\section{LA MUTACIÓN CONSTITUCIONAL: DE LA PRESIDENCIA ARBITRAL A LA PRESIDENCIA EJECUTIVA}

En el contexto de la revolución política que acabamos de describir podría parecer que lo único que va a sobrevivir del gaullismo es su arquitectura constitucional, esto es el sistema institucional de la V República. De hecho, el mantenimiento o no de dicho sistema fue objeto de debate político durante la campaña que precedió a las elecciones presidenciales. Mientras que la candidata socialista enarboló la bandera de la superación del marco constitucional actual y defendió la necesidad de construir una VI República, Sarkozy, rechazó esas iniciativas por considerarlas innecesarias.

Dos eran los ejes de la reforma constitucional propuesta por Royal: democracia participativa y descentralización política. La defensa de la democracia participativa como instrumento para superar la crisis de la democracia representativa fue contestada incluso por destacados dirigentes socialistas como Lionel Jospin que tuvo que recordar que Francia era y debía seguir siendo una democracia representativa. La democracia participativa propuesta por Royal parecía más bien un reconocimiento de sus propias carencias. A lo largo de la campaña, la candidata socialista, cuando no tenía o no quería dar una respuesta concreta, decía que ella "escucharía al pueblo francés". Dicho sin nin- 
guna intención peyorativa, no parece que los franceses quisieran relegar a la Presidencia de la República a la menesterosa condición de oyente. Los franceses, con su voto, dejaron claro que querían un Presidente que tuviera criterio propio. Por lo demás, la democracia participativa se traducía en la instauración de una suerte de jurados populares que pudieran controlar la actividad de los representantes políticos. En ninguna democracia constitucional del mundo existen instituciones similares y preciso es reconocer que en lo que se refiere a diseño constitucional no caben grandes innovaciones. La democracia es por definición participativa, los ciudadanos participan en los asuntos públicos, fundamentalmente a través de sus representantes. En eso consiste la democracia representativa. Las reformas constitucionales propuestas por Royal eran por tanto también, como el resto de sus propuestas políticas, ambiguas, e imprecisas. Finalmente, sus propuestas de descentralización política no encontraron, afortunadamente, ningún eco en la sociedad francesa, que, mayoritariamente no ve ventaja alguna en dicha descentralización a la que identifica con un aumento del número de funcionarios y del gasto público que no viene necesariamente acompañada de una mejora en la calidad de la prestación de los servicios públicos. La única propuesta concreta de la candidata era acabar con la acumulación de mandatos representativos. Esta sí que es una medida necesaria pero, probablemente, quedó oscurecida en el contexto de las demás.

Como es sabido, frente a ese discurso reformista, Sarkozy apostó por la continuidad de la V República. Sin embargo, sus primeros actos de gobierno y su propia personalidad indican que se está produciendo una mutación constitucional importante. Ya hemos dicho que en la $\mathrm{V}$ República la Jefatura del Estado es una pieza de singular importancia. Ello explica que cualquier modificación de su posición, inevitablemente, repercute sobre todo el sistema.

En última instancia, la Constitución de la V República es una Constitución ambigua. Ambigua en cuanto a la determinación de quién es el órgano que dirige la política. A. Hauriou -uno de los más lúcidos analistas del sistema político de la $\mathrm{V}$ República- la definía como «una diarquía desigual con incierta distribución de poderes y de responsabilidades" (entre el Presidente y el Primer Ministro). Según la letra de la Constitución, el poder de dirección reside en el Gobierno, y así el artículo 20 dispone que "el Gobierno determina y ejecuta la política de la nación". En ese contexto, se reservó al Jefe del Estado la dirección de la política exterior y de defensa. En la práctica, la Presidencia de la República se configuró, por tanto, como una figura arbitral que limitaba su actuación al escenario internacional. En todo caso, su verdadera posi- 
ción constitucional dependía de si contaba en la Asamblea Nacional con una mayoría favorable o no. De disponer de una mayoría parlamentaria afín, el Presidente nombraba a un Primer Ministro de su confianza. Ahora bien, normalmente, en esos casos, el Presidente dejaba en manos de aquél la dirección de la acción de gobierno. El Presidente permanecía así, por encima de la conflictividad social y política cotidiana. De Gaulle lo expresaba así: "Yo me ocupo de Francia, son mis ministros los que se ocupan de los franceses». Cuando el Presidente y la Asamblea eran de diferente signo ideológico, la cohabitación determinaba el cumplimiento literal de la Constitución, y, en ese caso, el Primer Ministro asumía la dirección del Estado. En definitiva, el equilibrio y la posición constitucional de las instituciones dependía, en buena medida de los resultados electorales. La ambigüedad del Texto Constitucional permitía esa pluralidad de situaciones. En ese contexto, la reducción del mandato presidencial de siete a cinco años, determinó la coincidencia temporal de las elecciones legislativas y presidenciales. Esa coincidencia alejó la posibilidad de nuevas "cohabitaciones" en la medida en que las elecciones legislativas se configuran como una mera ratificación de las presidenciales. Cabía suponer que a partir de ahora, todo Presidente contaría con una mayoría parlamentaria favorable. Lo que no estaba claro es si en este escenario el Jefe del Estado dejaría gobernar al Primer Ministro tal y como establece la Constitución o asumiría él directamente la función de dirección política de la República. La mutación constitucional sarkozyana consiste en haber eliminado definitivamente esa ambigüedad.

"Yo gobierno" dice Sarkozy una y otra vez. Y ello porque, a diferencia de sus predecesores en la $\mathrm{V}$ República, el actual inquilino del Elíseo es también el verdadero jefe del Gobierno. Sarkozy, según sus propias palabras se define como "un Presidente que gobierna». Como ha advertido Le Monde, el nuevo Jefe del Estado se comporta como un "hiperpresidente». Si a ello añadimos el hecho de que la "oleada azul» de las legislativas, aunque no ha supuesto una derrota tan humillante como pronosticaban algunos sondeos para el Partido Socialista, ha otorgado una muy amplia mayoría al partido del Presidente, no resulta exagerado afirmar que el nuevo Presidente se convierte en un auténtico monarca absoluto. Esto nos obliga a plantearnos el problema del equlibrio entre los poderes.

El Presidente de la República no puede comparecer ante la Asamblea Nacional ni es responsable ante ella. En la medida en que el Presidente no gobierne esa situación no es problemática, pero sí lo es en el supuesto de que el Jefe del Estado se convierta en el verdadero Jefe del Gobierno. Esto último es lo que ha ocurrido con Sarkozy. La Cons- 
titución de la $\mathrm{V}$ República no contiene mecanismos para controlar la acción política del Presidente. Este es el auténtico problema constitucional de la nueva era sarkozyana. Una V República concebida para un Presidente arbitral difícilmente podrá sobrevivir a una Presidencia ejecutiva.

Ahora bien, a pesar de que durante la campaña electoral y al margen de las tópicas referencias a la necesidad de modernizar las instituciones, adaptarlas a los nuevos tiempos, etc...Sarkozy no hizo mención alguna a la reforma constitucional, lo cierto es que el pasado 13 de julio, en la localidad emblemática de Bayeux, en el mismo lugar en que el General De Gaulle realizara una proclama parecida, anunció una futura reforma constitucional, que por su alcance puede conducir a una nueva República. En ese discurso se limitó a señalar las líneas maestras de la reforma: devolver poder al Parlamento, introducir un porcentaje de proporcionalidad en las elecciones para mejorar la representatividad de las cámaras, reducir su propio poder para nombrar cargos al frente de empresas e instituciones, permitir que el Presidente pueda expresarse ante la Asamblea Nacional, extender la jurisdicción del Tribunal de Cuentas al Presupuesto de la Jefatura del Estado, etc. Igualmente, anunció la inminente creación de una comisión de expertos (de 12 a 15) presidida por E. Balladur que deberá formular una serie de propuestas antes del próximo mes de noviembre. Sarkozy defendió la tesis de que la $\mathrm{V}$ República se encuentra en un callejón sin salida y que ello explica su decisión de abrir tanto el gobierno como la comisión asesora para la reforma constitucional a personalidades que no pertenecen a la derecha política.

Sea de ello lo que fuere, lo cierto es que los primeros cien días del mandato de Sarkozy se han caracterizado por la sistemática invasión presidencial de las competencias reservadas al Primer Ministro. Con reforma o sin ella, la $\vee$ República ya no es la misma. Como ha advertido el profesor Pérez Ayala, "desde el primer momento, el nuevo Presidente de la República ha desplegado una inusitada, y a veces compulsiva, hiperactividad en los más variados asuntos, llegando incluso a eclipsar por completo a su propio gobierno, incluido el Primer Ministro».

\section{LOS PRIMEROS CIEN DÍAS DE PRESIDENCIA.}

En sus primeros cien días, el Presidente ha intervenido directamente en todos los ámbitos de la vida política. En materia penal, propugnando la castración química de los pederastas; en materia laboral, abogando por una nueva regulación de los servicios mínimos; en el ámbito educativo, introduciendo criterios nuevos sobre la autonomía 
universitaria; en el campo de la inmigración, forzando la expulsión de cuotas fijas de extranjeros; en política fiscal, impulsando una nueva normativa sobre desgravación con efectos retroactivos de los intereses de los préstamos por compra de vivienda. Obligado resulta subrayar que esta omnipresencia ha permitido a Sarkozy cumplir sus cien días de mandato con unos índices de popularidad cercanos al 65 por ciento de aceptación.

Lo primero que debemos destacar es que si convencionalmente se suelen considerar los cien primeros días de mandato, como un periodo de calma que contrasta con el fragor de la campaña electoral (doble en este caso), en la que la posición concede un "periodo de gracia" al nuevo Presidente, quien se limita a conformar su equipo y fijar las directrices de su quinquenato, en el supuesto que nos ocupa, la hiperactividad presidencial otorga un carácter muy distinto a estos tres primeros meses. Lo acontecido en ellos nos permite extraer conclusiones claras sobre lo que cabe esperar de la presidencia Sarkozy.

a) La propuesta de castración química de los pederastas y otros delincuentes sexuales reincidentes es una de las iniciativas más polémicas de estos primeros meses. Ahora bien, dejando a un lado el contenido de la misma, lo que importa es subrayar que ella es expresión de una peligrosa forma de concebir la política a golpe de emociones. Ante la alarma social provocada por la violación de un niño de cinco años por un pederasta reincidente, Sarkozy ha propuesto modificar en octubre una Ley que llevaba diez días en vigor. La Ley que establece penas mínimas garantizadas para los multireincidentes y que es la décima que ha impulsado Sarkozy en los últimos cinco años. El sindicato de la magistratura USM, de orientación conservadora ha advertido que "es peligroso legislar a golpes de emoción" sobre temas muy complejos que requerirían un debate previo entre expertos. Le Monde, en un acertado editorial titulado precisamente "El Estado de emoción» (22 de agosto) recordó que "la política no puede contentarse con respuestas tajantes, ni limitarse a una sucesión de reacciones emocionales, casi epidérmicas, ante cualquier episodio que determine la vida pública (...) La responsabilidad de un Gobierno, y mucho más la de un jefe del Estado, es la de buscar soluciones, pero siempre teniendo en cuenta y explicando la complejidad de los problemas". En todo caso, lo más llamativo de esta iniciativa presidencial es su inutilidad. No hacía falta una nueva ley para evitar el odioso crimen que conmovió a la sociedad francesa. Hubiera bastado con aplicar la existente. La hospitalización y control psiquiátrico de delincuentes peligrosos es una obligación en Francia. Los brazaletes electrónicos que ahora fomenta Sarkozy existen desde el 2005. Ahora bien, debido a las restricciones presupuestarias, - ha de- 
nunciado el Sindicato de la Magistratura-, sólo los llevan diez reclusos. No es otra ley lo que hace falta para hacer frente al problema sino incrementar los medios administrativos, humanos y médicos. Empeñado en mostrar una reacción inmediata ante cada problema, el Presidente Sarkozy, como antes el ministro Sarkozy, exige aprobar nuevas leyes sin preocuparse de por qué no se aplican las existentes.

b) El objetivo de expulsar a 25000 inmigrantes ilegales antes de fin de año es otra de las iniciativas más polémicas del nuevo Presidente. Se trata de una propuesta que se sitúa en el contexto de la lepenización política de Francia a la que me he referido al comienzo de esta exposición. Las expulsiones ya han comenzado.

c) Una de las medidas estrella del programa presidencial, la desgravación retroactiva en la declaración de la renta de los intereses de los préstamos inmobiliarios ha sido desautorizada por el Consejo Constitucional. Sarkozy prometió que esa desgravación sería válida no sólo para los préstamos que se pidieran ahora sino también para los obtenidos durante los últimos cinco años, una opción personal del nuevo Presidente opuesta a la opinión del Ministro del Presupuesto, Eric Woerth. El Consejo Constitucional ha declarado que el efecto retroactivo (del que se beneficiaban tres millones de hogares) es contrario a la Constitución, pues no hay razón alguna por la que deba ser efectiva sólo durante cinco años y no seis, siete o doce. "Es un caso evidente de ruptura de la igualdad entre los contribuyentes", afirma el Consejo en su Decisión (Decisión 2007-555, de 16 de agosto) , y añade: «Ese trato desfavorable para los otros contribuyentes no queda justificado porque sirva para una redistribución del poder adquisitivo entre todos los franceses". Con esta decisión del Consejo Constitucional, el Presidente ha sufrido uno de sus primeros reveses. En última instancia y como ha subrayado el profesor Marc Carrillo, parece como si «también el Consejo Constitucional alertase al Presidente de los peligros del populismo económico".

d) Otra de las medidas de mayor alcance político y social de estos primeros cien días ha sido la aprobación en agosto de la "Ley sobre el diálogo social y la continuidad del servicio público en los transportes públicos terrestres". Con ella el Presidente ha cumplido su promesa de regular los servicios mínimos en los transportes públicos en caso de huelga. Los puntos más destacados de la ley son los siguientes: el transporte público funcionará en caso de huelga tres horas por la mañana y otras tres por la tarde; cada trabajador del sector del transporte deberá comunicar su voluntad de parar con dos días de antelación; si el paro durase más de siete días, será obligatorio ratificar la continuidad 
de la huelga mediante voto secreto. Por otro lado, el Primer Ministro defendió la necesidad de extender esa normativa a los educadores de escuelas e institutos. Con independencia de que una medida de tal carácter era necesaria, lo cierto es que con ella el Presidente ha plantado cara a los sindicatos franceses. Todos recuerdan las huelgas del otoño de 1995 que derribaron el Gobierno de Alain Juppé y llevaron a los socialistas al poder en la primavera de 1997. La opinión pública ha respaldado mayoritariamente la iniciativa presidencial y los sindicatos han anunciado una campaña de movilizaciones que no han tenido repercusión alguna, aunque han amenazado al Presidente con un "otoño caliente».

Será en otoño además cuando comiencen a debatirse toda una serie de proyectos relativos a la política social: la reforma del mercado laboral para flexibilizar la contratación, con la creación de un único contrato más sencillo; la reducción del número de funcionarios $(23.000$ para el próximo ejercicio presupuestario), especialmente en la enseñanza; la reforma de las pensiones, especialmente de los trabajadores de las compañías públicas, que resultan muy costosas; y la revisión del sistema de representación sindical y del diálogo social.

\section{LA NECESARIA REFUNDACIÓN (EN CLAVE EUROPEA) DEL SOCIALISMO FRANCÉS.}

El resultado de las elecciones presidenciales ha puesto claramente de manifiesto que no es posible ganar sin el respaldo de un partido poderoso. Aunque Sarkozy, inicialmente, no lo tuvo, una vez fue proclamado candidato oficial, todo el partido se volcó en su apoyo. En el caso de Royal, no es que el Partido Socialista no se movilizase por ella, que lo hizo, sino que dicho Partido dio una imagen de desunión que contribuyó, inexorablemente, a su derrota. Las elecciones primarias para la designación del candidato socialista provocaron unas heridas que todavía no han cicatrizado. Esa división se solapaba a una fractura política de mayor alcance en el seno del Partido Socialista en relación al proceso de integración europea. Esas divergencias impidieron formular una alternativa seria, realista, necesariamente europeista y socialdemócrata, al proyecto político de Sarkozy. Royal se proclamó heredera de François Mitterand, pero olvidó que la esencia de ese legado era y es el europeísmo. El Partido Socialista y Royal no han asumido lo que Mitterrand con gran lucidez percibió pronto: que el Estado Social en un solo país es ya una quimera; que es imprescindible construir una Europa Social. 
A juicio de muchos observadores extranjeros, entre los que me encuentro, Ségolène Royal a pesar de los errores cometidos, de fondo y de forma, encarnaba mejor que Sarkozy el viejo ideal revolucionario de la fraternidad. Frente a la bandera de la solidaridad que enarbolaba Royal, Sarkozy encarnaba un principio opuesto, la competencia. Por ello podemos decir que la competencia ha tomado el relevo de la solidaridad. La tarea más acuciante del partido socialista en Francia, como en el resto de los países de Europa, es construir un programa basado en un concepto de solidaridad más amplio, en la solidaridad europea.

El decano del periodismo frances Jean Daniel, quien llegó a calificar a Royal como "una esperanza de salud democrática", ha explicado su derrota en los siguientes términos. "Cuando decidió enfrentarse con los suyos, quiso prepararse sola, sin equipo, sin ayuda, decidida a desbaratar las trampas y deshacerse de los aparatos, y rechazando la tutela de los expertos que más podían contribuir a su proyecto. Con ello asumió también el riesgo de aumentar el número de sus enemigos, los celos de sus rivales y la impaciencia de sus mayores. El hecho de haber escogido el heroísmo de la soledad y la libertad le permitió imponerse, desde el exterior y con la ayuda de la opinión pública en un partido que no quería saber nada de ella. Sin esa decisión no habría sido candidata. Pero, al mismo tiempo, haber escogido la soledad le impidió poner a punto un proyecto extremadamente ambicioso: quería conciliar una especie de revolución cultural entre los socialistas franceses con una serie de pasos, por desgracia demasiado tímidos, para avanzar por la vía de la socialdemocracia».

La propia Royal reconoció en la que fue su primera aparición política del nuevo curso (en Melle, el 25 de agosto) haber cometido dos errores: "No hemos actualizado nuestras propuestas teniendo en cuenta los cambios que se producen en el mundo...confieso haber improvisado en determinados momentos". La autocrítica de la candidata socialista incluyó el reconocimiento de que su programa no contenía bases suficientemente sólidas para afrontar los desafíos actuales. El segundo error fue "no haber sabido organizar un partido moderno, de ventanas abiertas, pero capaz de organizarse para que todos tiremos en la misma dirección".

Ahora, Royal y el Partido Socialista pueden y deben aprender de los errores. La derrota del Partido Socialista ha puesto de manifiesto que sin un partido unido y sin un proyecto político definido no se puede ganar. La construcción de ese proyecto y la superación de sus fracturas internas es el desafío que el Partido Socialista deberá superar para estar en condiciones de competir por la Presidencia de la República en el 
2012. Este es el gran reto del próximo Congreso del PSF, previsto para octubre de 2008. Europa debería ocupar un lugar central en esos debates y en el proyecto político resultante. El otro reto es como hacer frente a la OPA que Sarkozy le ha dirigido y que ha provocado que los principales referentes del socialismo francés estén trabajando para el nuevo Presidente.

\section{REFLEXIÓN FINAL: UNA PRESIDENCIA «POSMODERNA»}

La principal conclusión que cabe extraer de esta sucinta exposición sobre el cambio político operado en Francia como consecuencia de la elección de N. Sarkozy como Jefe del Estado es que podemos y debemos certificar que la era del gaullismo ha concluido. Francia inicia una nueva era, el sarkozysmo. Y, en este sentido, no deja de resultar también paradójico que Francia, pionera y precursora de las grandes transformaciones políticas, llegue en este caso con un cuarto de siglo de retraso a protagonizar una revolución conservadora. Esta revolución de una u otra suerte, nos atrevemos a pronosticar, provocará la sustitución de la $\mathrm{V}$ República por un nuevo régimen. La $\mathrm{V}$ República fue concebida para una Presidencia arbitral y no podrá sobrevivir con un Presidente ejecutivo, con una "hiperpresidencia». En este sentido, denunciaba Le Monde el 22 de agosto: "A fuerza de querer demostrar su eficacia, todos los días y en todos los frentes, el hiperpresidente se sobrepasa. No sólo porque trastorna las instituciones, reduce a sus ministros a meros comparsas (...) sino también porque corre el riesgo de deslizarse por una peligrosa pendiente (...) que conduce a la demagogia".

Por otro lado, la V República fue expresión de un orden material de valores y reflejo de una idea del Estado que hoy están siendo puestos en cuestión. Su techo ideológico venía determinado por la defensa de un Estado fuerte, protector de los débiles, e independiente tanto de los poderes económicos, como de la superpotencia norteamericana. La victoria de Sarkozy supone el final de ese orden.

La campaña electoral puso de manifiesto la ambición ilimitada y el oportunismo político del candidato Sarkozy. Los tres primeros meses de la nueva presidencia nos han reportado una combinación de hiperactividad y omnipresencia, demagogia y populismo, característicos de lo que con gran agudeza, el profesor Sami Naír ha denominado "Presidencia posmoderna». La posmodernidad en política consiste en anteponer la ambición por el poder a la fe en las ideas. El indiscutible talento de Sarkozy reside en "haber comprendido que, en el fondo, un 
presidente no gobierna, sino las apariencias, pues el poder está en otras manos (finanzas, bolsa, medios)". Sarkozy es un Presidente posmoderno: "alguien que manipula el poder en una época en la que casi nadie cree en nada; en la que los valores pueden invertirse sin que eso tenga la menor importancia; en la que los gritos de los oprimidos y los olvidados del progreso son hábilmente sofocados por la sobreinformación mediática; en la que la explicación de la vida política se reduce, en los boletines informativos televisados, a una serie de acontecimientos inconexos, de sucesos a veces escandalosos y a veces trágicos; en la que la capacidad de analizar la realidad, de comprenderla, de actuar sobre ella, está desapareciendo, porque la razón crítica está siendo progresivamente desvirtuada".

¿Hacia dónde se dirige Francia? ¿Cuánto tiempo durará la sinfonía sarkozyana? ¿Será un breve y efímero paréntesis en la historia o logrará llevar a cabo una profunda transformación del modelo de sociedad francés?

Sea de ello lo que fuere, lo cierto es que Francia, como el resto de Estados europeos se encuentra en una encrucijada crítica. Los Estados europeos por sí solos no pueden afrontar los retos y desafíos de nuestro tiempo. Hacen falta respuestas globales para problemas que son también globales (inseguridad, inmigración, cambio climático, dependencia energética) $Y$ en ese contexto resulta preocupante el déficit de liderazgo político europeo. La nueva generación de políticos franceses, en particular, y europeos, en general, no está a la altura de los antiguos estadistas que protagonizaron el impulso integrador de Europa: Mitterrand, Kohl o Felipe Gonzalez. Por ello, creo que, puede resultar oportuno, aunque políticamente incorrecto, concluir esta exposición poniendo de manifiesto el significado y alcance históricos del relevo presidencial como relevo generacional. Aunque Chirac cometió un error fatal que lo enterró políticamente en vida convocando un referéndum que se sabía peligroso y resultó desastroso, el historiador Tony Judt ha advertido lo siguiente: "Ni Sarkozy, ni Royal, ni ningún otro de los que han disputado la sucesión de Chirac comparten su apreciación histórica de lo que está en juego en la construcción de Europa: por qué importa y por qué están jugando con fuego los que desean dividirla o diluirla».

El adios a Chirac es la despedida al último hombre de Estado europeo que por su propia trayectoria vital recuerda bien cuál es el futuro que puede aguardar a una Europa deshecha. 